\title{
Modulation of Membrane Microvisity by Binding of Low Density Lipoprotein (LDL) to LDL Receptors on Lymphocytes
}

\author{
Kazuko HiRamatsu* and Shigeru ARIMORI* \\ The Fourth Department of Internal Medicine, School of Medicine, Tokai University, \\ Isehara-City, Kanagawa-ken, 259-11 Japan
}

\section{SUMMARY}

\begin{abstract}
The effect of low density lipoprotein (LDL) on the microviscosity of cells has been examined to elucidate whether LDL induces altered microviscosity of cell membrane immediately after binding with LDL receptors. Peripheral blood B lymphocytes from healthy adults were used as a model of cells with LDL receptors, and T lymphocytes as well as lymphocytes from patients with familial hypercholesterolemia were used as control cells which have much less activity as LDL receptors than B lymphocytes. Microviscosity of cell membrane was determined by fluorescence polarization analysis of the fluorescent hydrocarbon probe, 1, 6-diphenyl-1,3,5-hexatriene. Elevation of microviscosity after incubation with $\mathrm{LDL}$ at $0^{\circ} \mathrm{C}$ for $30 \mathrm{~min}$ was induced only in $\mathrm{B}$ lymphocytes, but not in $\mathrm{T}$ lymphocytes or familial hypercholesterolemic lymphocytes. In parallel studies, it was shown that the activity of LDL receptor was observed exclusively in B lymphocytes but not in $\mathrm{T}$ lymphocytes or familial hypercholesterolemic whole lymphocytes.

It is concluded that binding of LDL to LDL receptors increases the microviscosity of membrane without internalization of LDL into cells. It is suggested that this method can be applied for the evaluation of LDL receptor activity under vaious clinical conditions.
\end{abstract}

Key words: membrane microviscosity, LDL receptor, B lymphocytes, T lymphocytes, hyperlipidemia.

\section{Introduction}

Microviscosity of cell membrane has been recognized as a parameter of cell membrane fluidity and has an important role for regulating membrane associated enzyme activity ${ }^{1)}$ and activity of cell surface receptors to various chemical agents ${ }^{2,3)}$.

In general, the relation between microviscosity and the lipid composition of a given membrane is that an increase in the ratio of cholesterol to phospholipid is correlated with an increase in membrane microviscosity and vice versa ${ }^{4}$ ). It has been reported that incubation of cells with LDL for more than 10 hours induces an increase in

\footnotetext{
* The Fourth Department of Internal Medicine, School of Medicine, Tokai University, Isehara-City, Kanagawa-ken, 259-11, Japan
}

microviscosity of cell membrane associated with an alteration of lipid composition of the membrane ${ }^{5)}$. However, it is presently unknown whether binding of lipoproteins to cell membrane immediately induces alterations in the microviscosity of cell membrane.

The purpose of this study was to elucidate whether microviscosity of cell membrane can be altered by LDL in a short time without incubation of cells at $37^{\circ} \mathrm{C}$. In other words, it is interesting to know whether LDL can alter microviscosity of cell membrane without internalization of LDL into cells. The cells employed in this study were peripheral blood B lymphocytes which have been reported to possess LDL receptors ${ }^{6}$. $T$ lymphocytes and lympocytes from patients with familial hypercholesterolemia have been used as controls since the activity of LDL on these cells is much less than that of B lymphocytes?). 


\section{Materials and Methods}

1) Subjects: Three healthy adults and two familial heterozygous hypercholesterolemic patients were investigated. These two patients were brothers, and their father was a hypercholesterolemic patient whose serum total cholesterol was $389 \mathrm{mg} / \mathrm{d} l$ and who had suffered from angina pectoris. The age and serum total cholesterol of these two patients were 19 and 17 years old, and $355 \mathrm{mg} / \mathrm{d} l$ and $403 \mathrm{mg} / \mathrm{d} l$ respectively.

2) Isolation of lymphocytes: Two hundred milliliters of heparinized venous blood was drawn from healthy adults and twenty milliliters from familial hypercholesterolemic patients. The blood samples were incubated for 1 hour at $37^{\circ} \mathrm{C}$ in silicon microcubes (KAC-II, purchased from Nippon Kotai Lab., Sagamihara, Japan) for depletion of monocytes. Lymphocytes were separated by Böyum's method ${ }^{8}$. The cells were washed twice with phosphate buffered saline $(\mathrm{pH}$ 7.2) containing $2 \%$ bovine serum albumin (Sigma. St. Louis Missouri).

3) Separation of $T$ and $B$ lymphocytes: A method reported by the International Union of Immunological Societies (ISIU) was employed for the separation of $\mathrm{T}$ and $\mathrm{B}$ lymphocytes from peripheral blood of healthy adults ${ }^{9)}$. A $\mathrm{T}$ lymphocyte rich population was collected by a nylon reticulum column. A B lymphocyte rich population was collected by Conray-Ficoll gradient centrifugation after formation of rosettes with sheep red blood cells (SRBC). The purity of the T and $B$ cells in these cell populations was determined by SRBC-rosette formation and immunofluorescent staining of cell surface immunoglobulin using FITC conjugated anti human $\operatorname{IgG}+\operatorname{IgM}+\operatorname{IgA}$ antisera produced in goats (Behring Werke AG Marburg-Larn, West Germany, Lot No. $686 \mathrm{H}$, F/P ratio: 3.2 ).

4) Separarion of low density lipoprotein: Human LDL (density 1.019-1.063) was obtained from the serum of a healthy adult after overnight fasting. LDL was isolated by differential ultracentrifugation (Hitachi 65P-7, Tokyo) ${ }^{10}$. The purity of the separated LDL was examined by agarose gel electrophoresis and analytical ultracentrifugation. Total cholesterol and triglyceride concentrations in this LDL were $163 \mathrm{mg} / \mathrm{d} l$ and $16 \mathrm{mg} / \mathrm{d} l$, respectively. LDL was dialysed extensively at $4^{\circ} \mathrm{C}$ overnight with a solution containing
$150 \mathrm{mM} \mathrm{NaCl}$ and $0.5 \mathrm{mM}$ ECTA-Na2. Protein content was quantitated by Lowry's method ${ }^{11)}$.

5) Quantitation of $\operatorname{IgG}+\operatorname{IgM}+\operatorname{IgA}$ bearing lymphocytes, LDL-binding lymphocytes and anti-beta-lipoprotein antiserum binding lymphocytes: The method for the quantitation of these lymphocytes was reported previously?). In brief, LDL was labelled with fluorescein isothiocyanate (FITC) using the method of Kawamura ${ }^{12}$. The lymphocytes were incubated at $4{ }^{\circ} \mathrm{C}$ for $30 \mathrm{~min}$ with FITC-labelled LDL and the number of LDL-binding lymphocytes was determined by an incident-type fluorescent microscope and expressed as a percentage of total lymphocytes. Anti-beta-lipoprotein antiserum binding lymphocytes and IgG + IgM+IgA binding lymphocytes were also determined using fluorescent microscopy.

6) Quantitation of lipids in lymphocytes: Lipids in lymphocytes were extracted by Folch's methods ${ }^{13)}$ and quantitated by thin layer chromatography with flame ionization detection employing cholesterol acetate as an internal standard ${ }^{14}$ ) The values of cholesteryl ester, triglyceride, free cholesterol and phospholipid were expressed as $\mu \mathrm{g}$ per $10^{6}$ lymphocytes.

5) Measurement of membrane microviscosity: Each whole lymphocyte, T lymphocyte and B lymphocyte sample was divided into two tubes at the concentration of $5 \times 10^{6}$ cells in 1 milliliter of $0.15 \mathrm{M} \mathrm{KCL}$. The fluorescent hydrocarbon, 1, 6-dipheny-1, 3, 5-hexatriene (DPH), was used as a probe for monitoring the microviscosity in the lipid core of the cell surface membrane. ${ }^{15)} 2 \times$ $10^{-3} \mathrm{M}$ DPH in tetrahydrofuran was first diluted 1,000 -fold with vigorously stirred agueous $0.15 \mathrm{M}$ $\mathrm{KCL}$. Stirring was continued for $15 \mathrm{~min}$ at $25^{\circ} \mathrm{C}$ and a clear and stable aqueous dispersion of $2 \times 10^{-6} \mathrm{DPH}$ which was practically void of fluorescence was obtained. One volume of cell suspension was mixed with one volume of the DPH dipersion and incubated at $25^{\circ} \mathrm{C}$ for $60 \mathrm{~min}$. The labelled cells were then washed twice and one tube was incubated with LDL and the other tube was with physiological saline at $0^{\circ} \mathrm{C}$ for $30 \mathrm{~min}$. After washing, the samples were immediately dipersed in $2 \mathrm{ml}$ of $0.15 \mathrm{M} \mathrm{KCL}$ and analysed for fluorescent measurements. All fluoresecnt measurements were carried out from $20{ }^{\circ} \mathrm{C}$ to $40{ }^{\circ} \mathrm{C}$ using Elscint Model MV-I microviscosimeter (Elscint, Ltd, Haifa, Israel). 


\section{Results}

1) Percentage of IgG + IgM + IgA bearing lymphocytes, FITC-LDL binding lymphocytes and anti-beta-lipoprotein antiserum binding lymphocytes in healthy adults and familial hypercholesterolemic patients: Table 1 shows that LDL binding lymphocytes in familial hypercholesterolemic patients were decreased significantly compared with those in healthy adults $(\mathrm{p}<0.001)$. There was no significant difference between patients and controls with regards to the percentages of IgG+ IgM+IgA bearing lymphocytes and anti-betalipoprotein antiserum binding lymphocytes.

2) Lipid contents in lymphocytes from healthy adults and familial hypercholesterolemic patients: Table 2 shows the lipid composition in lymphocytes after incubation with saline. The contents of triglyceride, free cholesterol and the molar ratio of free cholesterol to phospholipid were

Table 1 Percentage of immunoglobulin-bearing lymphocytes, LDL binding lymphocytes and antibeta-lipoprotein binding lymphocytes in healthy adults and familial hypercholesterolemic patients.

\begin{tabular}{lcc}
\hline & $\begin{array}{c}\text { Healthy } \\
\text { adults }\end{array}$ & $\begin{array}{c}\text { Familial } \\
\text { hyper- } \\
\text { cholester- } \\
\text { olemic } \\
\text { patients }\end{array}$ \\
\hline $\begin{array}{l}\text { B lymphocytes } \\
\text { (IgG+IgA+IgM) }\end{array}$ & $25 \pm 2$ & $23 \pm 2$ \\
$\begin{array}{l}\text { FITC-LDL binding } \\
\text { lymphocytes }\end{array}$ & $14.9 \pm 1.2$ & $3.0 \pm 0.2^{*}$ \\
$\begin{array}{l}\text { Anti-beta-lipoprotein anti } \\
\text { serum binding lymphocytes }\end{array}$ & $2.3 \pm 0.7$ & $2.0 \pm 0.1$ \\
\hline
\end{tabular}

All values are expressed as $\mathrm{M} \pm \mathrm{SD}(\%)$.

* $\mathbf{P}<0.001$

Table 2 Lipid content in lymphocytes of healthy subjects and familial hypercholesterolemic patients.

\begin{tabular}{lcc}
\hline & $\begin{array}{c}\text { Healthy } \\
\text { adults }\end{array}$ & $\begin{array}{c}\text { Familial hyper- } \\
\text { colesterolemic } \\
\text { patients }\end{array}$ \\
\hline Triglyceride & $18.1 \pm 9.7$ & $17.5 \pm 1.5$ \\
Cholesteryl ester & $11.1 \pm 3.8$ & $26.0 \pm 1.0^{*}$ \\
Free cholesterol (FC) & $15.1 \pm 4.8$ & $16.3 \pm 1.3$ \\
Phospholipid (PL) & $55.7 \pm 7.9$ & $62.1 \pm 1.5$ \\
FC/PL molar ratio & $0.56 \pm 0.11$ & $0.56 \pm 0.01$ \\
\hline
\end{tabular}

All values are expressed as $\mathrm{M} \pm \mathrm{SD}\left(\mu \mathrm{g}\right.$ per $10^{6}$ lymphocytes)

* $\mathrm{P}<0.005$ approximately equal in healthy and familial hypercholesterolemic lymphocytes. A significant increase in cholesteryl ester $(p<0.005)$ and a small degree of increase in phospholipid $(p>0.1)$ were observed in familial hypercholesterolemic lymphocytes. There was no difference in lipid composition in lymphocytes between incubation with saline and with LDL.

3) Comparison of microviscosity in whole lymphocytes, $T$ lymphocytes and B lymphocytes after incubation with LDL or saline: The purity of $\mathrm{T}$ and $\mathrm{B}$ lymphocytes was as follows. $90 \%$ of the $T$ lymphocyte rich population were SRBC rosette forming cells and $65 \%$ of the B lymphocytes were IgG $+\mathrm{IgM}+\mathrm{IgA}$ bearing cells. The percentage of monocytes in the $\mathrm{B}$ cell rich fraction after depletion by phagocytosis of silicon microcubes was less than $2 \%$ as determined by the staining of nonspecific esterase.

Plots of $\log \eta$ against $1 / \mathrm{T}$ for all lymphocyte samples gave straight lines between $20^{\circ} \mathrm{C}$ (3.41) and $40^{\circ} \mathrm{C}$ (3.19) (Figs 1, 2 and 3). There were no apparent phase transitions in the temperature range covered by our experiments.

The microviscosity of healthy $\mathbf{T}$ lymphocytes incubated with LDL was identical to those incubated with saline throughout the whole ranges of temparature examined in this study (Fig. 1).

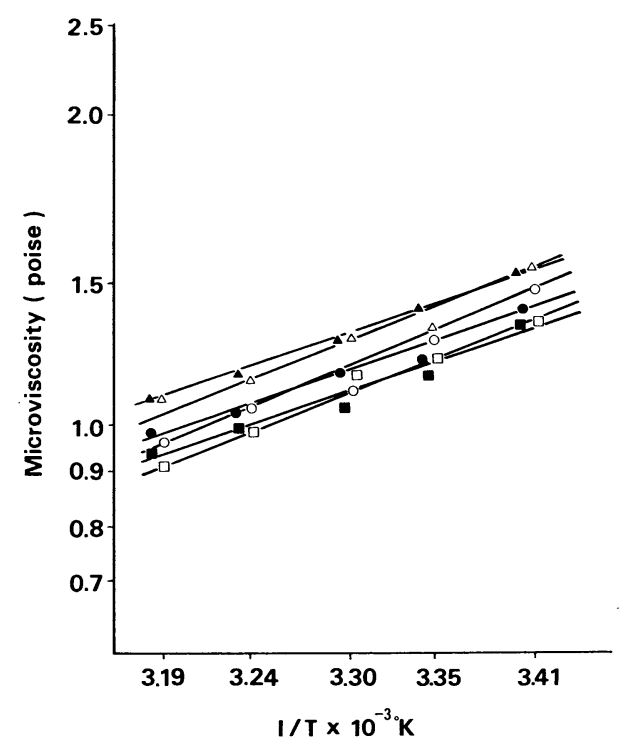

Fig. 1 Changes in microviscosity of healthy $T$ lymphocytes after incubation with physiological saline $(\bigcirc, \Delta, \square)$ and with $\operatorname{LDL}(\bullet, \Delta, \square)$ in three healthy adults. 


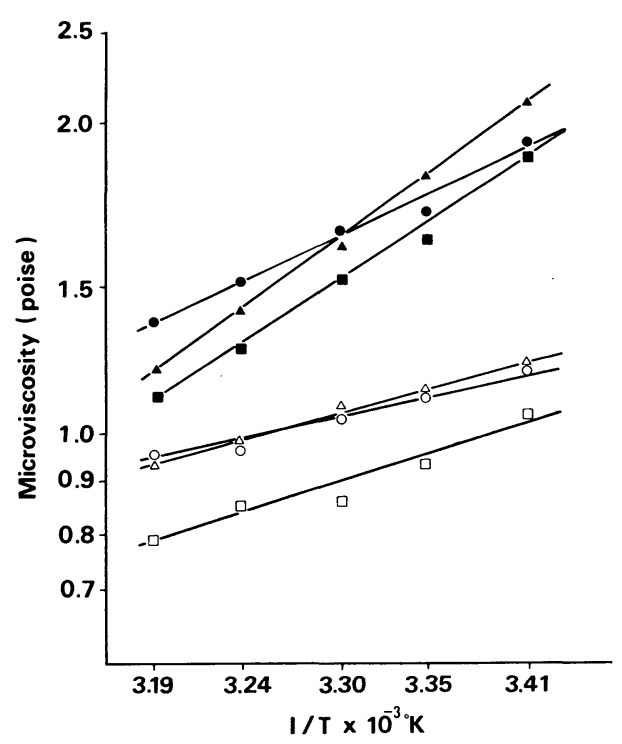

Fig. 2 Changes in microviscosity of healthy B lymphocytes after incubation with physiological saline $(\bigcirc, \Delta, \square)$ and with $\operatorname{LDL}(\bullet, \Delta, \mathbf{\square})$ in three healthy adults.

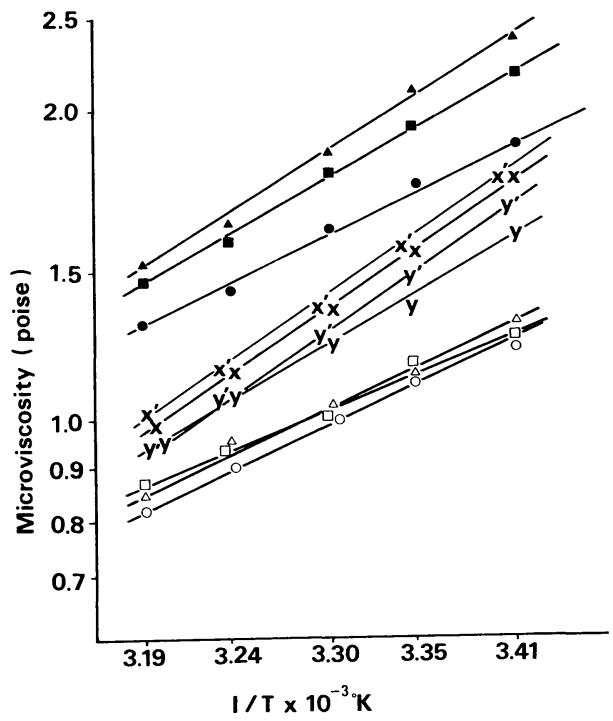

Fig. 3 Changes in microviscosity of healthy whole lymphocytes after incubation with physiological saline $(O, \Delta, \square)$ and with $\operatorname{LDL}(\bullet, \Delta$, a) in three healthy adults, and of whole lymphocytes after incubation with physiological saline $(\mathrm{X}, \mathrm{Y})$ and with $\mathrm{LDL}\left(\mathrm{X}^{\prime}, \mathrm{Y}^{\prime}\right)$ in two patients with familial hypercholesterolemia.
The microviscosity of healthy B lymphocytes incubated with LDL were elevated markedly at all temperatures compared with those incubated with saline, and the degree of the elevation in microviscosity was more prominant at lower temperatures than at high temperatures (Fig. 2)

Healthy whole lymphocytes incubated with LDL showed higher microviscosity than those with saline and the degree of the elevation was almost same with that observed in B lymphocytes. In comparison with the healthy whole lymphocytes, familial hypercholesterolemic lymphocytes did not show significant changes in microviscosity between cells incubated with and without LDL However, familial hypercholesterolemic lymphocytes showed significantly higher microviscosity than healthy lymphocytes after incubation with saline (Fig. 3).

\section{Discussion}

We have previously reported that LDL receptors exist exclusively on B lymphocytes but not on $\mathrm{T}$ lymphocytes in normal human peripheral blood $^{6}$. We have also reported that the number of LDL-binding lymphocytes are decreased significantly in patients with familiar hypercholesterolemia although the total number of B lymphocytes were not decreased in such patients ${ }^{7}$. The results obtained from this study demonstrated that the elevation in microviscosity induced by LDL was recognized only in B lymphocytes but not in $\mathbf{T}$ lymphocytes or in familial hypercholesterolemic lymphocytes, and that there were no changes in the molar ratio of free cholesterol to phospholipid and lipid composition after incubation with LDL. These results suggest that elevation of membrane microviscosity in lymphocytes is induced by the binding of LDL to LDL receptors on the membrane surface, and that this elevation of microviscosity is independent of the alteration in lipid composition of cells.

In healthy lymphocytes, the degree of increase in microviscosity induced by LDL in whole lymphocytes which contain $25 \%$ B lympocytes was almost the same as that in purified B lymphocytes. The reason of this phenomenon is obscure. The increased level of microviscosity in LDLincubated B lymphocytes might overshadow the stable microviscosity of $\mathrm{T}$ lymphocytes. No matter what the reason for the similarity in the increase of microviscosity of purified B lymphocytes and 
whole lymphocytes, it is indicated that whole lymphocytes can be utilized for the measurement of the effect of LDL on microviscosity, and thus amount of blood required for that measurement can be greatly saved.

The mechanism of the induction of higher microviscosity by LDL at lower temperatures is presently unknown. However such difference in microviscosity might be due to the difference of the amount of LDL on the cell surface.

Namely, LDL which binds with LDL receptor is incorporated into cells within a few minutes after elevation of the temperature from $20^{\circ} \mathrm{C}$ to $37^{\circ} \mathrm{C}$, and therefore the amount of LDL which remains on the cell surface is larger at low temperature ${ }^{16)}$.

There was no difference in the number of antibeta-lipoprotein antiserum binding lymphocytes between healthy adults and familial hypercholesterolemic patients, although higher microviscosity was observed in familial hypercholesterolemic lymphocytes after incubation with saline. The cells stained with FITC-conjugated antibeta-lipoprotein antisera were regarded as the cells possessing LDL on their surface in vivo. It is well established that the activity of LDL receptor on cell surfaces is decreased in patients with familial hypercholesterolemia as reported in fibloblast ${ }^{16)}$ and $B$ lymphocytes ${ }^{6}$. The amount of cell surface LDL on freshly obtained peripheral blood lymphocytes is, however, normal in patients with familial hypercholesterolemia as detected by the staining with FITC-conjugated anti-beta-lipoprotein antiserum. The mechanism this discrepancy is unknown.

The results from this study showed that cholesteryl ester in lymphocytes from patients with familial hypercholesterolemia increased significantly more than in healthy controls. Ho and his associates reported that the addition of LDL to healthy lymphocytes induced a six-fold accumulation of cholesteryl ester, whereas in the familial hypercholesterolemia homozygote cells no such accumulation of cholesteryl ester was detected ${ }^{17)}$. They also reported that the cholesteryl ester formation was supressed in familial homozygous hypercholesterolemic lymphocytes ${ }^{17}$ ) Analysis of lipid content in lymphocytes reported by previous investigators including $\mathrm{Ho}$ has been performed using long-term lymphoid cell lines. However, the content of free cholesterol, cho- lesteryl ester and other lipids in fresh lymphocytes has never reported in either healthy lymphocytes or familial hypercholesterolemic lymphocytes. Futher examination the synthesis of free cholesterol and cholesteryl ester and hydrolysis of cholesteryl ester in freshly isolated lymphocytes will be required to elucidate the machanism of cholesteryl ester accumulation in familial hypercholesterolemic lymphocytes.

In conclusion, the binding of LDL to LDL receptor on cell surfaces induces an increase in microviscosity of cell membrane in a short time without incorporation of LDL into cells. Peripheral blood B lymphocytes are useful to evaluate the interaction of LDL and LDL receptors on human cells. It is suggested that the assay of membrane microviscosity of B lymphocytes can be utilized as a simple laboratory test to survey patients with altered activity of LDL receptors under various clinical conditions.

This study was supported by a Grant-in-Aid for Developmental Scientific Research (A-577985).

\section{References}

1) Dipple, I. and Houslay, M. D.: The activity of glucagon-stimulated adenylate cyclase from rat liver plasma membranes is modulated by the fluidity of its lipid environment. Biochem. J., 174: 179-190 (1978).

2) Shinitzky, M. and Inbar, M.: Microviscosity parameters and protein mobility in biological membranes. Biochim. Biophy. acta 433: 133-149 (1976).

3) Shattil, S. J. and Cooper, R. A.: Membrane microviscosity and human platelet function. Biochemistry, 15: 4832-4837 (1976).

4) Shnitzky, M., Dianoux, A. C., Gitler, C. and Weber, G.: Microviscosity and order in the hydrocarbon region of micelles and membranes determined with fluorescent probes. Biochemistry, 10: 2106-2113 (1971).

5) Petitou, M., Tuy, F., Rosenfeld, C., Mishal, Z., Paintrand, M., Jasnin, C., Mathe, G. and Inbar, M.: Decreased microviscosity of membrane lipids in leukemic cell. Two possible mechanisms. Proc. Natl. Acad. Sci. USA, 75: 2306-2310 (1978).

6) Hiramatsu, K., Sakai, H., Endoh, M. and Arimori, S.: Surface properties of LDL-binding lymphocytes in human peripheral blood. Immunol., 39: 311-316 (1980).

7) Hiramatsu, K., Sakai, H., Endoh, M. and Arimori S.: Significance of LDL binding lymphocytes in patients with hyperlipidemia. Tokai J. Exp. Clin. 
Med., 5: 51-58 (1980).

8) Böyum, A.: Separation of leukocytes from blood and bone marrow. Scan. J. Clin. Invest. Suppl., 21: 97 (1968).

9) International Union of Immunological Societies (ISIU): Identification, enumeration and isolation of B and T cell lymphocytes from human peripheral blood. Clin. Immunol. Immunopathol, 3: 584-594 (1975).

10) Hatch, F. T. and Lees, R. S.: Plasma lipoprotein analysis. Advances Lipid Res., 6: 33-36 (1968).

11) Lowry, O. H., Rosebrough, N. J., Farr, A. J. and Randall, R. J.: Protein measurement with the folin phenol reagent. J. Biol. Chem., 193: 265-275 (1951).

12) Kawamura, AJr: Fluorescence antibody techniques and their applications. Tokyo, University of Tokyo Press, 44 (1977).

13) Folch, J. P., Lees, M. and Sloane, S.: A simple method for the isolation and purification of total lipids from animal tissues. J. Biol. Chem., 226: 497-509 (1957).

14) Hiramatsu, K. and Arimori, S.: Rapid determination of lipid in healthy human lymphocytes. J. Chromatogr. 227: 423-431 (1982).

15) Inbar, M. and Shinitzky, M.: Decrease in microviscosity of lymphocyte surface membrane associated with stimulation induced by concanavalin A. Eur. J. Immunol., 5: 166-170 (1975).

16) Brown, M. S. and Goldstein, J. L.: Receptormediated endocytosis: Insights from the lipoprotein receptor system. Pro. Natl. Acad. Sci. USA, 76: 3330-3337 (1979).

17) Ho, Y. K., Brown, M. S., Kayden, H. J. and Goldstein, J. L.: Binding, internalization, and hydrolysis of low density lipoprotein in long-term lymphoid cell lines from normal subjects and patients with homozygous familial hypercholesterolemia. J. Exp. Med., 144: 444-455 (1976). 